\title{
Ocean acidification through the lens of ecological theory
}

\author{
Brian Gaylord, ${ }^{1,14}$ Kristy J. Kroeker, ${ }^{1}$ Jennifer M. Sunday, ${ }^{2}$ Kathryn M. Anderson, ${ }^{2}$ James P. Barry, ${ }^{3}$ \\ Norah E. Brown, ${ }^{2}$ Sean D. Connell, ${ }^{4}$ Sam Dupont,${ }^{5}$ Katharina E. Fabricius, ${ }^{6}$ Jason M. Hall-Spencer, ${ }^{7}$ Terrie \\ Klinger, ${ }^{8}$ Marco Milazzo, ${ }^{9}$ Philip L. Munday, ${ }^{10}$ Bayden D. Russell, ${ }^{4}$ Eric Sanford, ${ }^{1}$ Sebastian J. Schreiber, ${ }^{11}$ \\ Vengatesen Thiyagarajan, ${ }^{12}$ Megan L. H. Vaughan, ${ }^{2}$ Steven Widdicombe, ${ }^{13}$ and Christopher D. G. Harley ${ }^{2}$ \\ ${ }^{1}$ Bodega Marine Laboratory and Department of Evolution and Ecology, University of California-Davis, Bodega Bay, \\ California 94923 USA \\ ${ }^{2}$ Department of Zoology and Biodiversity Research Centre, University of British Columbia, Vancouver, \\ British Columbia V6T 174 Canada \\ ${ }^{3}$ Monterey Bay Aquarium Research Institute, Moss Landing, California 95039 USA \\ ${ }^{4}$ Southern Seas Ecology Laboratories, School of Earth and Environmental Sciences, and Environment Institute, University of Adelaide, \\ South Australia 5005 Australia \\ ${ }^{5}$ Department of Biological and Environmental Sciences, University of Gothenburg. The Sven Lovén Centre for Marine Sciences, \\ 45178 Fiskebäckskil, Sweden \\ ${ }^{6}$ Australian Institute of Marine Science, PMB 3, Townsville, Queensland 4810 Australia \\ ${ }^{7}$ School of Marine Science and Engineering, University of Plymouth, Plymouth, United Kingdom \\ ${ }^{8}$ School of Marine and Environmental Affairs, University of Washington, Seattle, Washington 98105 USA \\ ${ }^{9}$ Dipartimento di Scienze della Terra e del Mare, University of Palermo, Palermo, Italy \\ ${ }^{10}$ ARC Centre of Excellence for Coral Reef Studies, School of Marine and Tropical Biology, James Cook University, Townsville, \\ Queensland, Australia \\ ${ }^{11}$ Department of Evolution and Ecology, University of California, Davis, California 95616 USA \\ ${ }^{12}$ Swire Institute of Marine Sciences and School of Biological Sciences, The University of Hong Kong, Pokfulam, Hong Kong SAR \\ ${ }^{13}$ Plymouth Marine Laboratory, Plymouth, Devon PL13DH United Kingdom
}

Abstract. Ocean acidification, chemical changes to the carbonate system of seawater, is emerging as a key environmental challenge accompanying global warming and other humaninduced perturbations. Considerable research seeks to define the scope and character of potential outcomes from this phenomenon, but a crucial impediment persists. Ecological theory, despite its power and utility, has been only peripherally applied to the problem. Here we sketch in broad strokes several areas where fundamental principles of ecology have the capacity to generate insight into ocean acidification's consequences. We focus on conceptual models that, when considered in the context of acidification, yield explicit predictions regarding a spectrum of population- and community-level effects, from narrowing of species ranges and shifts in patterns of demographic connectivity, to modified consumer-resource relationships, to ascendance of weedy taxa and loss of species diversity. Although our coverage represents only a small fraction of the breadth of possible insights achievable from the application of theory, our hope is that this initial foray will spur expanded efforts to blend experiments with theoretical approaches. The result promises to be a deeper and more nuanced understanding of ocean acidification and the ecological changes it portends.

Key words: anthropogenic climate change; ecological models; ecological theories; elevated carbon dioxide; environmental threats; global environmental change; marine stressors.

\section{INTRODUCTION}

There is a rich history of using conceptual, analytical, and computational models to explain pattern in nature. Many of these models derive substantially from research on marine systems. Keystone and foundation species constructs (Paine 1969, Dayton 1972), the intermediate

Manuscript received 27 April 2014; revised 12 August 2014; accepted 27 August 2014. Corresponding Editor: J. F. Bruno.

${ }^{14}$ E-mail: bpgaylord@ucdavis.edu disturbance hypothesis (Connell 1978, Sousa 1979a), frameworks for considering succession (Connell and Slatyer 1977, Sousa 1979b), theory for open populations (Roughgarden et al. 1985), environmental stress models (Menge and Sutherland 1987), the storage effect's role in species coexistence (Chesson and Warner 1981), structures for assessing indirect effects (Wootton 1994), evaluations of the importance of facilitation (Bruno et al. 2003) - all have been developed or sharpened through research on life in the sea. 
Now, in an era of increasing ecological uncertainty induced by human activities, such models carry particular significance. In addition to unifying ideas and explaining biological patterns, they assist with prediction, notably in anticipating outcomes tied to global environmental change. The manifestation of such change is of course varied, as it can originate from many drivers (e.g., warming, eutrophication, hypoxia, overharvesting, habitat loss, species invasions). Here, we focus on ocean acidification (OA; Caldeira and Wickett 2003), a shift in the carbonate system of seawater that is generating widespread concern. Our aim is to consider an abbreviated set of conceptual models, among them some of ecology's seminal constructs, that link to known characteristics of OA, highlighting how the application of theory can reveal testable hypotheses and guide thinking. While incomplete as presented, we argue that such an approach can spur a more rapid and comprehensive understanding of the consequences of this marked perturbation to the oceans.

OA derives from the entry of human-produced carbon dioxide $\left(\mathrm{CO}_{2}\right)$ into the sea. When $\mathrm{CO}_{2}$ enters seawater, it increases dissolved $\mathrm{CO}_{2}$ concentrations while also combining with water to form carbonic acid $\left(\mathrm{H}_{2} \mathrm{CO}_{3}\right)$, which mostly dissociates into bicarbonate $\left(\mathrm{HCO}_{3}{ }^{-}\right)$and hydrogen ions. The hydrogen ions produced in this process decrease the $\mathrm{pH}$ of seawater. They also react with carbonate $\left(\mathrm{CO}_{3}{ }^{2-}\right)$ ions that are additionally present in seawater to form more bicarbonate ions, reducing the concentration of $\mathrm{CO}_{3}{ }^{2-}$, which in turn decreases the saturation state of seawater with respect to calcium carbonate minerals (aragonite and calcite) used by organisms in shells and skeletons. The sum of these chemical changes can elevate energetic costs associated with acid-base regulation and production of calcified structures by organisms. The scope of perturbations is also substantial: concentrations of hydrogen ions in seawater globally have risen $30 \%$ since preindustrial times, at a rate unprecedented in the geologic record (Hönisch et al. 2012). Indeed, these shifts are occurring fast enough that in some regions (e.g., within the California Current of the northeastern Pacific; Hauri et al. 2013), the yearly mean $\mathrm{pH}$ may fall below the lower bound of contemporary seasonal variation within 35 years.

\section{A Refinement of Perspective}

The field of OA has quickly generated a multitude of studies demonstrating biological effects of elevated seawater $\mathrm{CO}_{2}$ (reviewed in Doney et al. 2009, Hofmann et al. 2010, Kroeker et al. 2010, 2013a, Barry et al. 2011). This work has been invaluable for contextualizing the consequences of observed and projected environmental changes. At the same time, a cautionary observation may be in order. Organismallevel effects of OA are routinely described as "impacts," even though analogous physiological experi- ments focusing on temperature would likely characterize outcomes as "responses," entirely expected and often readily managed outside of extremes. The distinction between impact and response is only semantic, but connotation carries weight. True negative impacts, at least in the ecological and conservation sense, imply a disadvantageous effect on population abundance or distribution. OA-related declines in growth, survival, reproduction, and other parameters could indeed have such consequences, and existing studies suggest a strong possibility that they will. Nevertheless, an imperative remains to place individual-level performance into an appropriate ecological context (e.g., long-term exposures demonstrating lifetime fitness costs in a natural setting). Other reviews have also articulated this latter point (Russell et al. 2012, Godbold and Calosi 2013).

An accompanying issue is that current research focuses predominantly on how individual species experience direct effects of OA. Work in the area of global warming demonstrates that most temperatureassociated cases of severe population decline originate not from direct physiological responses to heat, but rather from modified species interactions (Cahill et al. 2013). Analogous trends arise in lake acidification (e.g., Locke and Sprules 2000), and it can be anticipated that consequences of OA will accrue similarly. This situation creates challenges, and also tremendous opportunity to exploit decades of progress in dissecting relationships, drivers, and responses of natural systems, as elucidated by many of ecology's most influential workers.

For the purpose of linking to existing spheres of understanding, we identify three general "pressure points" of OA that intersect with theory. These pressure points represent nodes of environmental-biological interaction where OA appears to exhibit an especially strong capacity to drive ecological change. In what follows we employ the terms "OA" and "elevated $\mathrm{CO}_{2}$ " interchangeably given their close relationship.

1. Elevated $\mathrm{CO}_{2}$ acts as a resource for primary producers.-Inorganic carbon is rarely limiting in the sea, but most is available as bicarbonate rather than $\mathrm{CO}_{2}$. Although marine macrophytes often employ carbon-concentrating mechanisms that facilitate $\mathrm{CO}_{2}$ uptake or convert bicarbonate to $\mathrm{CO}_{2}$ for photosynthesis, these mechanisms require energy (Giordano et al. 2005). Under OA, some species appear to use increased seawater $\mathrm{CO}_{2}$ to supplement or bypass their carbon concentrating machinery (e.g., Cornwall et al. 2012), and this response may allow cost savings, enhancing growth in many seagrasses and algae (Harley et al. 2012, Koch et al. 2013). Outcomes also vary across species, with elevated $\mathrm{CO}_{2}$ enabling some taxa to gain a relative advantage. In particular "weedy" species (e.g., fleshy, mat-forming algae) that can rapidly exploit other nutrients like nitrate when available seem to perform well under OA (e.g., Russell et al. 2009). 
Calcifying species, by contrast, often perform more poorly (Kroeker et al. 2010).

2. OA induces energetic costs for many consumers.In marine animals, elevated seawater $\mathrm{CO}_{2}$ and the accompanying change in $\mathrm{pH}$ often necessitates allocation of additional energy to acid-base regulation (Pörtner 2008). We therefore expect an appreciable subset of herbivores and carnivores to experience negative effects to at least some degree. Costs in calcifying consumers could be increased further if organisms must work harder under OA to maintain the elevated $\mathrm{pH}$ conditions and higher calcium carbonate saturation states local to sites of calcification that facilitate mineral formation (e.g., Gattuso et al. 1998, Ries 2011, Comeau et al. 2013, Waldbusser et al. 2013).

3. Biotic interactions will play crucial roles.-The direct resource benefits of $\mathrm{CO}_{2}$ for primary producers, and OA's direct energetic costs for other species, represent only part of the issue. As alluded to above, the biggest unknown in OA research is how species will respond within the context of their communities. It is almost certain that many of the most striking consequences of $\mathrm{OA}$ will arise through altered species interactions (e.g., Fabricius et al. 2011, Falkenberg et al. 2013, Kroeker et al. 2013b, McCormick et al. 2013). The "what and the how" of these interspecific linkages is where ecological theory has much to offer.

Here we consider how these pressure points integrate with a spectrum of conceptual models. The examples we present are purely illustrative, focus primarily on benthic systems, and neglect for the most part other stressors such as elevated temperature and/or low dissolved oxygen that often accompany OA. Thus our coverage does not represent the full scope of possibilities. It does, nonetheless, hint at the value of such integration for generating new hypotheses and paving new avenues for inquiry.

\section{Testable Predictions Emerging From Theory}

\section{Population distributions and connectivity}

Insights from eco-physiological models.-A defining goal of ecology is to understand patterns of organism distribution and abundance. Temperature operates as a recognized determinant of the former, as evidenced by poleward, elevational, and depth-related shifts in species ranges due to global warming (Parmesan and Yohe 2003, Perry et al. 2005, Poloczanska et al. 2013). Although ocean carbonate parameters appear less important in limiting range (with the possible exception of depth constraints on some deep-water calcifiers; Guinotte et al. 2006), OA may interleave with effects of rising temperature. Thermal performance curves provide a framework for examining this issue. With warming alone, habitats yielding adequate performance for survival will tend to follow the movement of isotherms toward higher latitudes and deeper depths (Fig. 1). Distributions of species constrained by temperature will often track similarly, assuming range

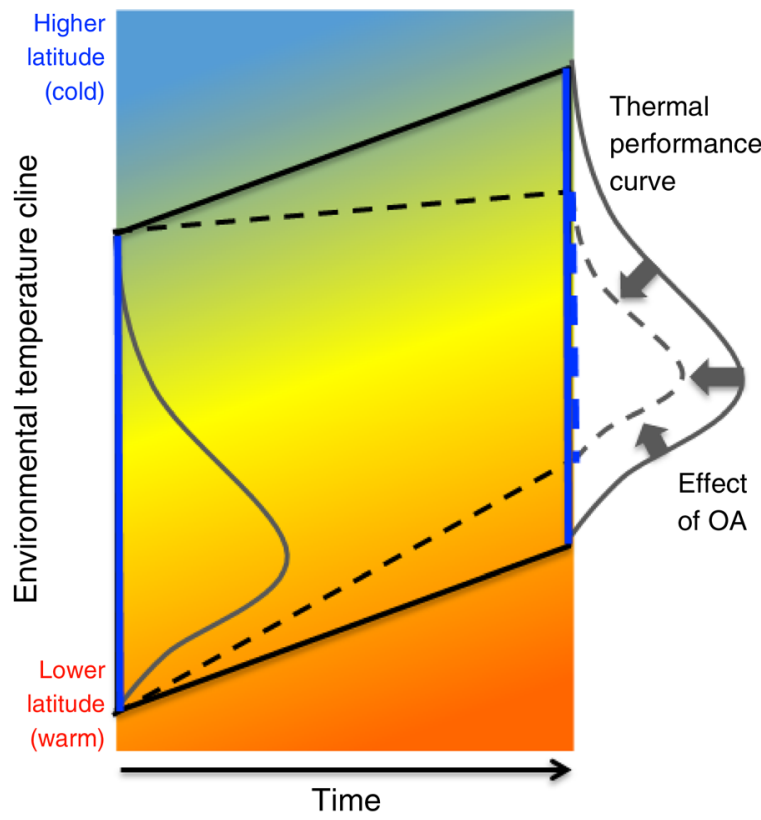

FIG. 1. Species ranges may contract as well as shift when ocean acidification (OA) accompanies warming. A species' thermal performance curve, where performance rises nearer the apex, dictates accessible habitat (blue vertical lines), the latter of which tends to track environmental isotherms (colored background). Gray block arrows indicate how ocean acidification may induce a narrowing of the thermal performance curve, driving a contraction in range breadth (blue dashed line).

shifts can proceed fast enough to keep up (Thomas et al. 2004, Sunday et al. 2012). It has been proposed, however, that OA will often impose additional physiological stresses that narrow the breadth of the thermal performance curve (e.g., Pörtner 2008). To the extent that such narrowing arises (see, e.g., counterpoints in Gräns et al. [2014]), it could cause equatorward range limits to contract faster than the rate of movement of isotherms, and poleward range limits to expand slower. The net effect would be smaller overall ranges, and ranges for which equatorward boundaries shift more dramatically than poleward ones.

Metabolic theory.-Temperature-related effects on distributional pattern also intersect with attributes of life history, which may in turn link back to OA. Many marine species produce dispersing larvae whose oceanographic transport affects population connectivity, persistence, or the positioning of range limits (Gaylord and Gaines 2000, Cowen et al. 2006). Work by O'Connor et al. (2007) shows that pelagic larval durations (PLD) of a variety of invertebrates depend on temperature in a fashion consistent with scaling relationships derived from basic thermodynamic principles (i.e., from metabolic theory; Brown et al. 2004). This framework projects strong declines in PLD with increasing temperature, especially among species whose 


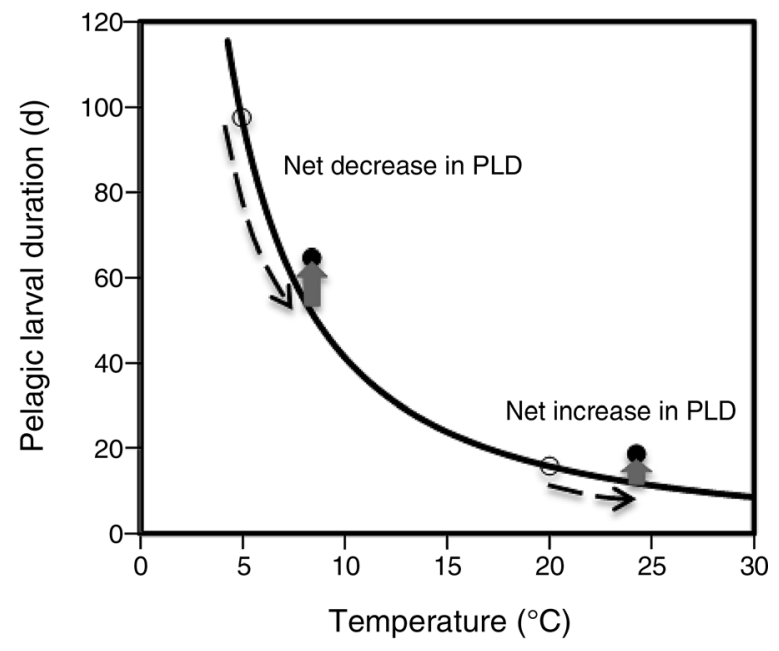

FIG. 2. Projected combined effects of rising seawater temperature and $\mathrm{OA}$ on invertebrate pelagic larval durations (PLD). A $4^{\circ} \mathrm{C}$ warming (dashed arrows) coupled with an order of magnitude $10 \%$ longer PLD due to OA-induced developmental delays (gray block arrows) causes either a net decrease or increase in larval duration, depending on prevailing ocean temperatures. Open and solid circles represent conditions prior and subsequent to assumed environmental changes, respectively. Solid line corresponds to the population-averaged curve of O'Connor et al. (2007).

larvae disperse in polar to temperate waters. OA could modulate these patterns. Ocean acidification slows larval development in some taxa (Dupont et al. 2010, Gazeau et al. 2013), opposing consequences of warming. Because predicted temperature-associated shifts in PLD attenuate with decreasing latitude, OA's effects could conceivably take precedence over those of temperature in warmer temperate seas, inducing net increases in larval duration (Fig. 2). Shifts in population connectivity might follow due to the dual influence of PLD on dispersal distances (O'Connor et al. 2007; see also Dawson 2014), and on the durations over which larvae are exposed to high mortality while in the plankton (Rumrill 1990). Variation in species' responses to OA and warming, including altered timing and magnitudes of offspring production, and accelerated depletion of energy stores in non-feeding larvae (see, e.g., Byrne 2011, Figueiredo et al. 2014) could further complicate connectivity patterns.

Population models.-The potential for OA to induce a range of individual-level responses, including ones that act simultaneously or otherwise interact, emphasizes the very real need in OA research to evaluate rigorously whether observed shifts in demographic and life history parameters do in fact alter population growth or stability. This point carries particular weight when populations experience additional, often unexamined, aspects of environmental or community variation whose effects might or might not swamp those of OA. Requisite analyses will benefit from the legacy of quantitative approaches embodied in classic population and metapopulation theory (e.g., Nisbet and Gurney 1982, Hanski 1998), as well as more recent techniques that include dynamic energy budget and integral projection models (see, e.g., Kooijman 2010, de Roos and Persson 2013, Muller and Nisbet 2014, Rees et al. 2014).

\section{Consumer-resource relationships}

Foraging theory.-A number of classic models in ecology address pairwise dynamics of interacting species (e.g., Lotka-Volterra predator-prey and competition models). These simple representations provide both powerful frameworks for analysis and also impetus for more in-depth extensions. Optimal foraging theory operates as one such extension. It explains why certain predators specialize on one or a few prey species, while others consume many. A core assumption is that consumers act to maximize net energetic benefits per time. Thus predators preferentially target prey with greater energy content, or prey that can be captured and processed more easily. OA relates to such principles in multiple ways. Elevated seawater $\mathrm{CO}_{2}$ often decreases growth rates, resulting in individuals of smaller size for a given age. If a specialist predator consumes only individuals of one species that are smaller under OA, the predator might elevate its per capita consumption to maintain the same energy intake (Sanford et al. 2014). Nonspecialist predators, by contrast, may expand their dietary breadth or exclude a formerly preferred prey if the abundance or energetic value per individual of the prey declines. OA may also increase prey vulnerability (e.g., through impaired shell integrity; Gaylord et al. 2011, Amaral et al. 2012; see also Doropoulos et al. 2012), or elevate the energetic needs of predators; such changes could further modulate the balance of energy intake vs. expenditure. Similar considerations apply to metabolic shifts deriving from $\mathrm{CO}_{2}$-induced warming, which could combine with or offset consequences of OA.

Induced defenses in predator-prey theory.-In some situations, induced defenses of prey (e.g., production of thicker shells in response to predator chemical cues; Trussell 1996) become attenuated under OA (Bibby et al. 2007). Such reductions in defense could operate in isolation, or in combination with direct biogeochemical effects of OA on protective structures. In either case, heightened prey vulnerability and any resulting targeting of a prey species by a predator may alter the stability and character of consumer-prey dynamics (e.g., through a switch from Type III to II predator functional response; Hammill et al. 2010).

\section{Community processes and interactions}

The relative importance of competition, predation, and facilitation continues to be a subject of great interest in ecology. Research has focused on factors dictating when and why one type of interaction dominates over another, as well as on indirect effects 
A) Sessile species

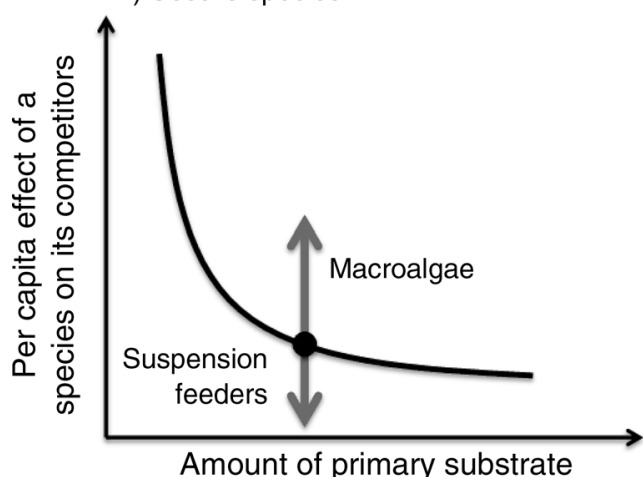

B) Mobile consumers

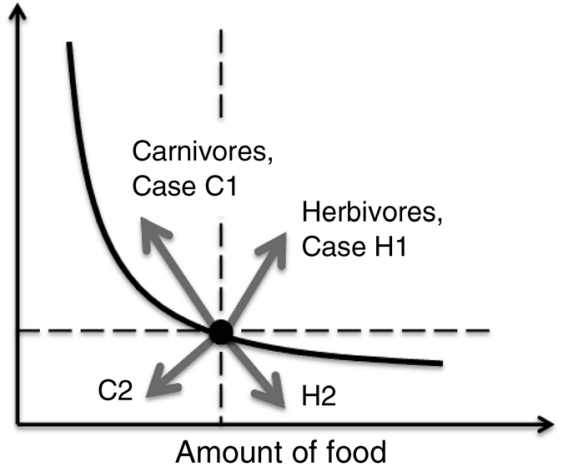

FIG. 3. Hypothesized influence of OA (gray arrows) on the per capita competitive effect of one species on another when either (A) space or (B) food is limiting. Solid curves indicate the traditional pattern where, if all else is equal, the competitive effect of a focal taxon is higher in habitats with fewer resources, and lower in more bountiful habitats. (A) OA does not affect the amount of primary substrate (the sum of open and occupied space), but often increases growth in macroalgae and decreases growth in sessile consumers, altering their competitive effects on other space occupants. (B) Mobile consumers may experience greater or lesser food under OA, together with altered energetic demands, creating a more complex suite of potential outcomes. For herbivores, if increased energetic demands under OA outweigh increases in their algal food, and organisms respond by elevating their feeding activities, their competitive effects may intensify (Case H1). If physiological stresses from OA induce strong reductions in growth or cause metabolic depression, per capita demands on food may fall to a degree that competitive effects decline (Case H2). Analogous patterns arise for carnivores (Cases $\mathrm{C} 1$ and $\mathrm{C} 2$ ), except that $\mathrm{OA}$ is expected to more often decrease prey abundance than increase it. Although not shown explicitly, there will also be herbivores that do not experience elevated food conditions under OA and so fall into sectors to the left of the vertical dashed line, as well as carnivores that fall into rightward sectors of the graph where food availability rises.

arising from interactions that propagate through a food web. We briefly explore how several of these themes link to OA.

Competition theory.-Competition depends on resource limitation. It increases in intensity as shared resources become less available, and declines when resources are plentiful. Species that utilize resources more similarly compete more strongly. Ocean acidification can mediate competition among species because it influences both the supply of resources and the demand for them. For example, higher inorganic carbon levels in seawater often boost rates of primary production by marine algae and plants (Kroeker et al. 2010), thereby increasing the availability of food for herbivores, but also potentially altering food quality and palatability (Arnold et al. 2012, Rossoll et al. 2012). At the same time, OA elevates the energetic needs of many consumers, especially calcifying species that may bear an extra energetic burden under acidified conditions. These coupled responses create a complex interplay among the physiological susceptibility of organisms to OA, the availability of resources, and the intensity of competition.

Classic models in which multiple species use a common, limiting resource (e.g., MacArthur 1970) provide insight into how OA might change the competitive effect of one species on another (here defined as the percent reduction, per individual of a focal species, in the intrinsic population growth rate of its competitor). If all other factors are held constant, a focal species will compete more intensely if it lives in a habitat with low resource availability, and less intensely if resources are plentiful (solid lines in Fig. $3)$. OA then alters the competitive effect of the focal species in the context of that habitat. In benthic marine species that compete for primary substrate (composed of both open and occupied space; Fig. 3A), outcomes may be relatively straightforward. Macroalgae often exhibit greater growth under elevated $\mathrm{CO}_{2}$, increasing their competitive effects, whereas sessile consumers like suspension feeders may demonstrate a reduced competitive effect if they incur elevated energetic demands and thus decreased growth. The situation may be more complicated for mobile consumers (Fig. 3B). These species often compete for food instead of space, and may affect competitors to a greater or lesser extent depending on the relative magnitudes of OA-induced changes in energetic demand and food availability (the latter modulated by any behavioral traits that might allow organisms to respond to altered resources). One of several possible outcomes is that sensitive grazers whose algal food becomes more abundant under OA may elevate their feeding rates, enabling them to combat higher physiological costs, but only through greater competition with other herbivores. Carnivores that consume the grazers, on the other hand, may experience not only higher energetic costs but also reduced numbers of prey. Depending on whether the carnivores feed more to maintain a similar energy balance or not, their effects on competitors could increase or decrease. Further complexities arise if OA differentially alters the competitive ability of species to the extent that 

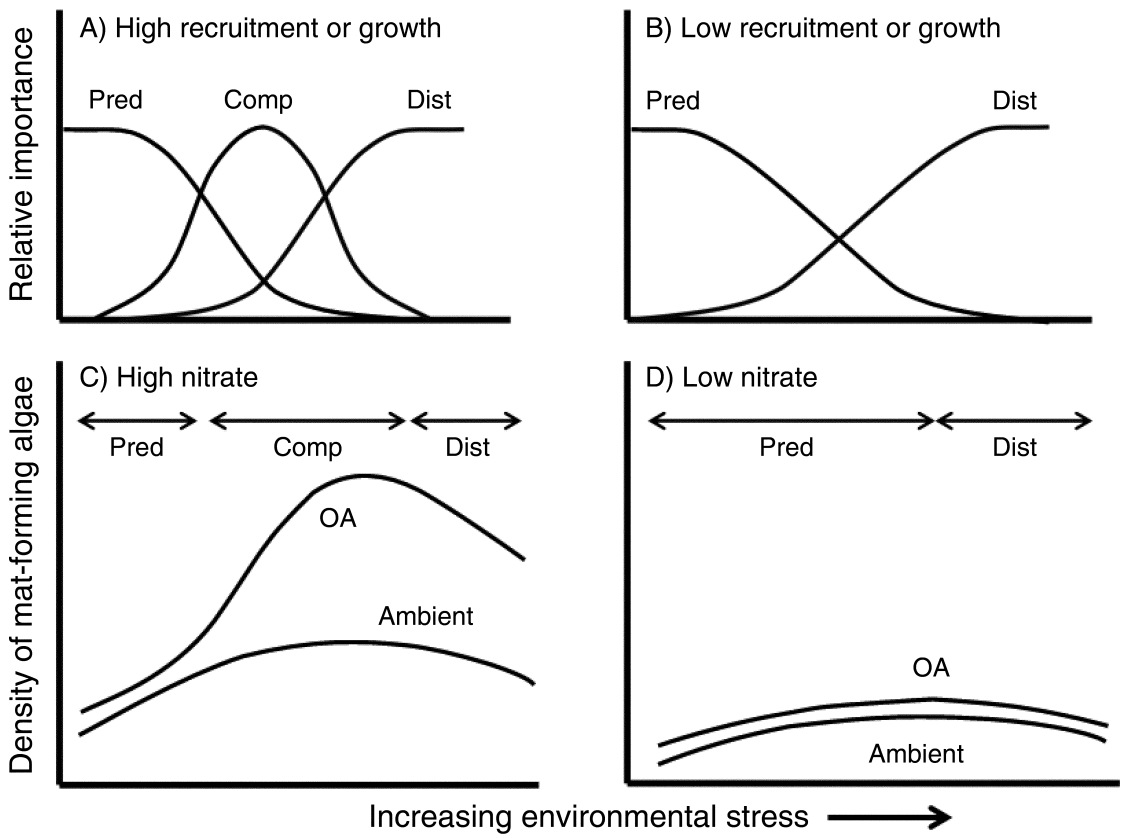

FIG. 4. (A, B) Menge-Sutherland model applied to the basal trophic level of a community when recruitment or growth is either high or low, showing the relative importance of predation (Pred), competition (Comp), and disturbance (Dist) across a range of environmental stress. (C, D) Predictions based on this model regarding the degree to which mat-forming algae in the basal trophic level will increase in density under OA. Double-headed arrows depict ranges of stress over which certain processes take precedence. When nutrients such as nitrate are plentiful, the $\mathrm{CO}_{2}$ fertilization effect of $\mathrm{OA}$ may differentially benefit mat-forming algae, bolstering algal densities, especially if calcifying predators (grazers here) are also impaired. This effect persists until physical stresses reach levels where disturbance dominates. When nitrate is limiting, growth of algae is intrinsically lower, they cannot take advantage of elevated $\mathrm{CO}_{2}$, competition among basal species for space becomes less important, and grazer effects predominate over a wider portion of the stress gradient. Under these latter conditions, mat-forming algae may exhibit little OA-associated capacity to exclude or overgrow other species.

patterns of dominance shift (e.g., McCormick et al. 2013, McCoy and Pfister 2014).

Environmental stress models.-The role of competition can also depend on how predation and disturbance vary across a range of environmental stress. Classic explorations of this issue (Menge and Sutherland 1987; see also Bruno et al. [2003] for elaborations incorporating facilitation) focused on benthic communities where environmental stressors of interest include extreme temperatures or salinities, anoxia, eutrophication, wave forces, or other agents of physical or physiological disruption. At the basal trophic level, first predation, then competition, and finally disturbance are predicted to dominate as environmental stresses rise (Fig. 4A). A key assumption underlying this trend is that mobile predators, including grazers, exhibit greater susceptibility to stresses. Another expectation is that competition at the basal level enters as an important process only in systems where substantial recruitment or growth lead to high densities of individuals and thus decreased availability of living space (compare Fig. 4A, B).

The environmental stress framework has utility for interpreting what may be one of OA's more pervasive consequences. A variety of studies in both tropical and temperate systems suggest marked increases in weedy, mat-forming algae under OA (Connell et al. 2013). These taxa appear capable of differentially exploiting the fertilization effect of $\mathrm{CO}_{2}$, which allows them to outcompete other constituents of the benthos. Because scenarios of this kind conflict with a simple conceptualization of $\mathrm{OA}$ as another agent of environmental stress (i.e., a factor causing movement along the $\mathrm{x}$-axes of Fig. 4A, B), we categorize elevated $\mathrm{CO}_{2}$ as an independent perturbation. In particular, OA tends to shift the system from situations like those of Fig. 4B to those of Fig. 4A by boosting algal growth. We also note some corollaries to this trend. When factors other than carbon availability are limiting for algae, or if physical conditions are benign (low values on $x$-axes of Fig. 4A, B), then OA will not increase the importance of competition; in these latter scenarios, grazing could conceivably hold mat densities to reduced levels even in the face of OA. Such considerations suggest less striking increases of mats under reduced light or in oligotrophic habitats where minimal nitrate constrains growth regardless of carbon availability (Fig. 4D), or in low-stress locations (small $x$-axis values in Fig. 4C, D). Modulating this hypothesis is the observation that calcified species comprise a large fraction of grazers in many reef systems and are thought to be disproportionately 
vulnerable to OA (e.g., Hall-Spencer et al. 2008, Christen et al. 2013). Abundant food can counter the detriments of OA (e.g., Thomsen et al. 2013), but in cases where it doesn't and grazing pressure falls, for example due to declines in average size or abundance of herbivores (i.e., as in case $\mathrm{H} 2$ of Fig. 3B), modest increases in mat-forming algae could ensue even under benign environmental and low-nutrient conditions. Further complexities could arise from impaired recruitment of any strongly interacting species within the system (see, e.g., Kuffner et al. 2008, Albright et al. 2010, Green et al. 2013, Webster et al. 2013).

Trophic theory.-The potential for $\mathrm{OA}$ to both increase primary production and decrease consumer performance raises the possibility that $\mathrm{OA}$ might simultaneously influence bottom-up and top-down processes in food webs. Oksanen et al. (1981) projected alternating increases in abundance within successively higher trophic levels as resources for primary producers rise, a result borne out in some studies (e.g., Wootton and Power 1993). In more complex food webs with competing herbivores in middle trophic levels, increased production at the lowest level often drives shifts in species composition, with increases in more predation-resistant grazers (Leibold 1996). Whether similar trends will arise under high $\mathrm{CO}_{2}$ is unclear; a number of communitylevel studies suggest declines in calcifying taxa that often include grazers (e.g., Hall-Spencer et al. 2008, Hale et al. 2011, Christen et al. 2013). Regardless of their precise manifestation, bottom-up food web changes could be important. They could also be accompanied by effects of OA on top predators. The classic keystone sea star, Pisaster ochraceus, increases its growth when exposed to elevated seawater $\mathrm{CO}_{2}$ (Gooding et al. 2009). Although its size-specific feeding rates do not climb significantly, leaving unclear the trophic implications, at least some marine food webs are susceptible to vertically propagating changes (i.e., trophic cascades; Strong 1992, Shurin et al. 2002). A relatively unexplored issue is the potential for OA to alter food web links involving parasites or pathogens (MacLeod and Poulin 2012), perhaps through effects on host immune responses (e.g., Bibby et al. 2008).

Models of trait-mediated interactions.-Studies of indirect effects such as those responsible for trophic cascades increasingly emphasize trait-mediated processes that alter interactions not because of changes in species abundance, but through shifts in other factors such as behavior (Werner and Peacor 2003). For example, consumption of a primary producer might be suppressed because a grazer detects a predator and remains in a refuge. Emerging data suggest that OA may strongly modify a suite of such trait-mediated indirect interactions through its effects on neurosensory pathways (Munday et al. 2010, Nilsson et al. 2012). In particular, GABA receptors in marine fish appear strongly sensitive to $\mathrm{pH}$, with elevated seawater $\mathrm{CO}_{2}$ causing dramatic changes in homing, habitat selection, predator avoidance, and recruitment. Further work is required to determine whether effects of $\mathrm{OA}$ on such behaviors arise primarily in vertebrates, or more broadly in a range of taxa. If they do (and there is evidence that such may be the case; Watson et al. 2014), OA-induced shifts in traitmediated indirect interactions should probably be considered a distinct pressure point.

\section{Species diversity}

Keystone and foundation species concepts.-Ecologists have recognized for decades that certain species play especially important roles in communities and ecosystems (Paine 1969, Dayton 1972). Of particular interest are those that induce disproportionately strong effects relative to their abundance (keystone species), or those that generate crucial habitat supporting many other taxa (foundation species). The former often increase diversity through partial or periodic removal of dominant species, allowing inferior competitors to persist within the community. The latter often increase diversity through the provision of resources and living space, or by the amelioration of physical stress. An obvious way in which OA may drive changes in community structure (e.g., diversity) and the functioning of ecosystems, therefore, is through impacts on keystone or foundation organisms. A growing body of work demonstrates effects on many such species. Corals exhibit a wide range of negative responses, particularly when combined with other stressors (reviewed in Hoegh-Guldberg et al. 2007; see also Fabricius et al. 2014). Oysters show sensitivity, especially during the larval phase (e.g., Miller et al. 2009, Talmage and Gobler 2010, Hettinger et al. 2012, Dineshram et al. 2013). Reef-forming vermetid gastropods exhibit adverse effects (Milazzo et al. 2014). Echinoderms, including keystone sea star species, show numerous negative responses along with some positive ones (Gooding et al. 2009, Dupont et al. 2010). Canopy-forming kelps and seagrasses benefit directly from OA (Palacios and Zimmerman 2007, Hepburn et al. 2011, Koch et al. 2013), but also can experience reduced recruitment due to exclusion by "weedier" species of mat-forming algae (Connell and Russell 2010). Thus, data are accumulating regarding many of these key taxa, aiding assessment of population- and community-level consequences. For instance, on rocky shores of the northeastern Pacific, field transition data and modeling suggest ties between low $\mathrm{pH}$ and declines in the competitive dominant mussel (also considered a foundation species; Wootton et al. 2008), possibly due to negative effects of $\mathrm{OA}$ on larvae (Gaylord et al. 2011, Frieder et al. 2014) or decreased attachment strength in sessile stages (O'Donnell et al. 2013). 


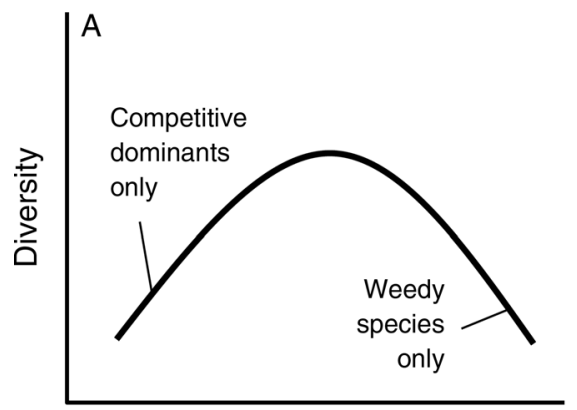

Disturbance level

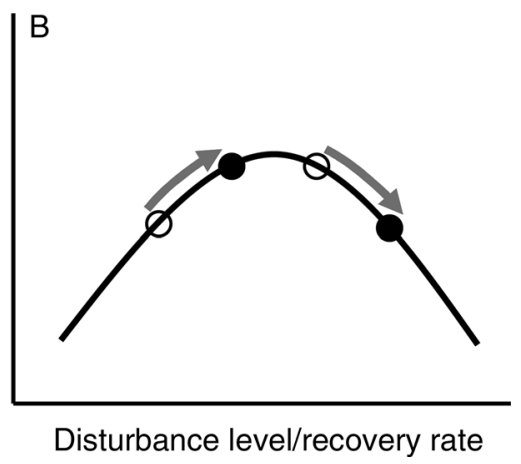

FIG. 5. Effect of OA on predictions of the intermediate disturbance hypothesis. In the classic model (A), diversity is expected to peak at modest levels of disturbance where good competitors (but poor colonizers) can persist in the community alongside good colonizers (but poor competitors). Because the disturbance level expressed on the abscissa is implicitly quantified only relative to the recovery rate of the system (which appears explicitly as a divisor in panel B), the tendency for OA to slow ecological recovery rates induces a rightward shift in the effective level of disturbance, even if the actual disturbance regime does not change. Possible example cases are indicated with gray arrows as shifts from the positions of the open circles to the solid circles.

The intermediate disturbance hypothesis.-It is well understood that abiotic factors interact with biotic ones to influence diversity. Landmark papers by Connell (1978) and Huston (1979) posit that moderate levels of environmental disturbance promote the coexistence of greater numbers of species. Higher levels of disturbance result in the elimination of poorly colonizing or damage-prone species, while lower levels result in loss of inferior competitors. Only at intermediate disturbance levels does the broadest spectrum of species persist (Fig. 5A). Implicit in this conceptualization, however, is the fact that the level of disturbance is interpretable only when considered relative to the recovery rate of the system. If recolonization proceeds more slowly, the operational level of disturbance will be higher even if its physical manifestation is identical. Given that OA often leads to delayed development, increased larval mortality, decreased growth, or reduced reproduction, OA could slow ecological recovery rates in many cases. The result would be a shift to a higher effective level of disturbance within any given system. Depending on the initial state of the system, such an elevation in disturbance could increase or decrease diversity, even as it uniformly benefits "weedier" species (Fig. 5B). In cases where macroalgal foundation species engender most of the diversity, enhanced growth rates under OA might shorten post-disturbance recovery rates, reversing the pattern.

Theory regarding consequences of biodiversity.-Because larger pools of species can promote a variety of ecological "services" (e.g., more biomass, faster nutrient cycling, greater stability in the face of disturbance, increased invasion resistance; Loreau et al. 2001), considerable attention has focused on implications of declining diversity. This body of work has not yet been linked strongly to OA (Widdicombe and Spicer 2008, Barry et al. 2011), but there are clear potential connections. For example, theory suggests that diversity among functionally similar taxa broadens the spectrum of responses to environmental perturbations, fostering compensatory dynamics in which population increases of stress-tolerant taxa counteract population declines in stress-intolerant taxa (Yachi and Loreau 1999). Such compensation appears relevant to $\mathrm{OA}$, where reductions in the abundance of $\mathrm{CO}_{2}$-sensitive herbivores can be accompanied by increases in acidification-tolerant grazers (e.g., Kroeker et al. 2011). Whether OA-associated compensation can operate with equivalent strength in communities governed by simpler food webs, or in higher trophic levels where diversity is intrinsically lower, awaits further study. Additional research is also required to ascertain how compensatory processes might change in coming decades, given that nonrandom extinctions (e.g., arising less frequently in $\mathrm{CO}_{2}$-resilient taxa) might not only bolster communitywide tolerance to OA in the short term, but could also decrease functional breadth and the scope for future compensatory responses (Ives and Cardinale 2004). Other diversity-associated properties, including capacities for carbon sequestration and resistance to species invasion, are also now being examined in light of OA (e.g., Christen et al. 2013, Vaz-Pinto et al. 2013).

\section{Acclimatization and adaptation}

Most ecological models ignore physiological acclimatization to environmental change (i.e., phenotypic plasticity), as well as genetic adaptation over the longer term. However, there is a strong role for theory in formalizing links between both of these processes and global change (Chevin et al. 2010). Acclimatization and its experimental equivalent, acclimation, can influence the ability of organisms to cope with OA (e.g., Form and Riebesell 2012, Crook et al. 2013), as can phenotypic changes induced across generations (e.g., via maternal provisioning of offspring; Parker et al. 

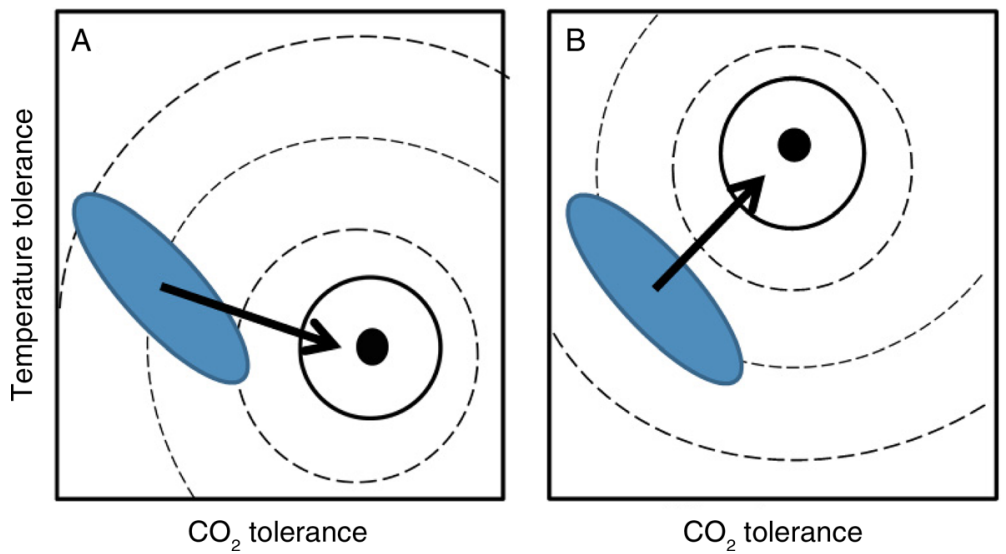

FIG. 6. Potential match or mismatch between genetic correlations underlying two traits (blue ellipses) and gradients in fitness (contour levels shown as dashed lines), in the face of different scenarios of environmental change within coastal upwelling systems. (A) Increases in upwelling (bringing naturally $\mathrm{CO}_{2}$-rich waters to the surface with effects of OA layered on) accompanied by minimal changes in seawater temperature, causing the axis of genetic correlation to mostly align with the fitness peak (black circle). (B) Little change in upwelling accompanied by warming and increases in $\mathrm{CO}_{2}$ induced exclusively by $\mathrm{OA}$, resulting in an axis of selection (black arrow) that orients orthogonally to the pattern of genetic variation. Modified after Sunday et al. (2014).

2012). Whether such plasticity increases the time available for adaptation to catch up, or slows the pace of adaptation by shifting the mean phenotype in a direction that weakens selective pressure, remains less clear. Some theory suggests that acclimatization in the face of abrupt environmental change will spark a phenotypic jump that is followed first by rapid evolution of increased plasticity, then by a slow decay of the latter as allelic changes accrue (i.e., through genetic assimilation; Lande 2009). Determining the generality of such outcomes is central to accurately predicting future outcomes in an elevated- $\mathrm{CO}_{2}$ world (Sunday et al. 2014).

Models of selection. - Given the pace at which OA is occurring, adaptation in many species will rely on changes in the relative frequencies of existing alleles rather than on new mutations (Munday et al. 2013). This point holds especially strongly for taxa with long generation times, and applies acutely to those with small population sizes or low genetic diversity. A further complication arises when multiple stressors act simultaneously. In such situations, adaptive responses can vary depending on how different axes of genetic variation interact over the fitness landscape. Theory indicates that, if positive or negative correlations exist between genetic axes, selection can operate either faster or slower than expected (e.g., Munday et al. 2013, Sunday et al. 2014).

The four major upwelling systems of the world provide an instructional example of where genetic correlations could bear relevance. In these systems, deeper and colder waters that are innately high in $\mathrm{CO}_{2}$ rise to the surface near the coast (Feely et al. 2008). This process operates most intensely within certain latitudinal bands. Thus, in the California Current, populations in some northerly locales experience colder and more-elevated- $\mathrm{CO}_{2}$ seawater than populations to the south. One might expect this gradient to have selected for negative correlations between genotypes conferring high temperature tolerance and ones fostering $\mathrm{CO}_{2}$ resistance, especially among species unaffected by aerial emergence (Fig. 6A). Although most climate models suggest future increases in upwelling (Bakun 1990, Snyder et al. 2003), some uncertainty exists as to whether upwelling will increase across all systems and domains within them (e.g., Narayan et al. 2010). Stronger upwelling would layer additional $\mathrm{CO}_{2}$ onto the $\mathrm{OA}$ burden while simultaneously opposing broader warming trends, producing a pattern consistent with the conjectured genetic correlation. This situation could facilitate adaptation (Fig. 6A). With unchanged or decreased upwelling, by contrast, temperatures and $\mathrm{CO}_{2}$ may rise in concert, deviating from historical trends. In this alternative scenario, the axis of selection would orient orthogonally to the conjectured pattern of genetic variation, and the capacity for appropriate adaptation could decline (Fig. 6B).

Eco-evolutionary concepts. - Other areas of ecological theory are sufficiently young that connections to OA have not yet been made. The arena of eco-evolutionary dynamics (the "newest synthesis;" Schoener 2011) remains almost entirely unexamined in an OA context. Yet the timescales of global change relevant to society are exactly those over which interactions between evolution and ecology could exhibit profound relevance. Strong selection is required for evolutionary processes to influence ecological performance (Ellner 2013). Recent studies suggest that OA can indeed operate as a strong selective force; for example, appreciable shifts in allele frequencies appear possible even over single generations in larval sea urchins 
exposed to OA (Sunday et al. 2011, Kelly et al. 2013, Pespeni et al. 2013). This capacity for evolutionary change might be a consequence of high standing genetic variation in these organisms, and could itself derive from spatiotemporally variable selection operating within a diverse mosaic of coastal oceanographic conditions (see, e.g., Hofmann et al. [2011] for examples of such spatial variation). Whether beneficial adaptation per se will occur reliably over ecological timescales, however, remains uncertain and likely differs across species. Some taxa show strong adaptation after a few hundred generations of exposure to elevated $\mathrm{CO}_{2}$ while others exhibit evolutionary changes of little obvious advantage (Collins and Bell 2004, Lohbeck et al. 2012). Clearly, additional attention to this issue is required, especially given that further complexity in eco-evolutionary interactions arise when multiple selective pressures act at once (Ellner 2013, Munday et al. 2013). This final point serves also as a reminder that the various conceptual models presented above do not operate in isolation but rather blur together across individual, population, and community levels.

\section{Looking forward}

As Niels Bohr famously observed, prediction is very difficult, especially about the future. This statement applies particularly well to nascent fields like the ecology of ocean acidification, where many hypotheses remain untested and new observations are accumulating rapidly. It is our contention that understanding, and perhaps successfully predicting, ecological responses to OA will be aided greatly by a deeper consideration of theory. Such an approach will require a new generation of natural and manipulative experiments that explicitly test hypotheses generated by models. A key element of this line of research will be more concerted attention to, and quantification of, many of the processes most central to ecology's guiding concepts. High priorities for research include dissecting OA's effects on population dynamics, its influence on the character of species interactions, and its capacity to alter the functioning of ecosystems, along with any modifying influences of acclimatization and adaptation. On a final note, the application of theory to patterns and processes associated with $\mathrm{OA}$ should produce reciprocal benefits, as ocean acidification, a unique global-scale manipulation, enables ecologists to test, refine, and extend ecological theory.

\section{ACKNOWLEDGMENTS}

This article emerged from a working group funded by the Peter Wall Institute for Advanced Studies. We are grateful to R. Bechmann, R. Carpenter, P. Edmunds, B. Hales, G. Hofmann, J. Largier, J. Ries, J. Stillman, A. Todgham, and G. Waldbusser for helpful discussions, and three anonymous reviewers and the editor for valuable comments. Research support was provided by the U.S. National Science Foundation, the National Science and Engineering Research Council of Canada, and several of our institutions.

\section{Literature Cited}

Albright, R., B. Mason, M. Miller, and C. Langdon. 2010. Ocean acidification compromises recruitment success of the threatened Caribbean coral Acropora palmata. Proceedings of the National Academy of Sciences USA 107:20400-20404.

Amaral, V., H. N. Cabral, and M. J. Bishop. 2012. Effects of estuarine acidification on predator-prey interactions. Marine Ecology Progress Series 445:117-127.

Arnold, T., C. Mealey, H. Leahey, A. W. Miller, J. M. HallSpencer, M. Milazzo, and K. Maers. 2012. Ocean acidification and the loss of phenolic substances in marine plants. PLoS ONE 7:e35107.

Bakun, A. 1990. Global climate change and intensification of coastal ocean upwelling. Science 247:198-201.

Barry, J. P., S. Widdicombe, and J. M. Hall-Spencer. 2011. Effects of ocean acidification on marine biodiversity and ecosystem function. Pages 192-209 in J.-P. Gattuso and L. Hansen, editors. Ocean acidification. Oxford University Press, Oxford, UK.

Bibby, R., P. Cleall-Harding, S. Rundle, S. Widdicombe, and J. Spicer. 2007. Ocean acidification disrupts induced defenses in the intertidal gastropod Littorina littorea. Biology Letters 3:699-701.

Bibby, R., S. Widdicombe, H. Parry, J. Spicer, and R. Pipe. 2008. Effects of ocean acidification on the immune response of the blue mussel Mytilus edulis. Aquatic Biology 2:67-74.

Brown, J. H., J. F. Gillooly, A. P. Allen, V. M. Savage, and G. B. West. 2004. Toward a metabolic theory of ecology. Ecology 85:1771-1789.

Bruno, J. F., J. J. Stachowicz, and M. D. Bertness. 2003. Inclusion of facilitation into ecological theory. Trends in Ecology and Evolution 18:119-125.

Byrne, M. 2011. Impact of ocean warming and ocean acidification on marine invertebrate life history stages: Vulnerabilities and potential for persistence in a changing ocean. Oceanography and Marine Biology: An Annual Review 49:1-42.

Cahill, A. E., et al. 2013. How does climate change cause extinction? Proceedings of the Royal Society B 280:20121890.

Caldeira, K., and M. E. Wickett. 2003. Anthropogenic carbon and ocean $\mathrm{pH}$. Nature 425:365.

Chesson, P. L., and R. R. Warner. 1981. Environmental variability promotes coexistence in lottery competitive systems. American Naturalist 117:923-943.

Chevin, L.-M., R. Lande, and G. M. Mace. 2010. Adaptation, plasticity, and extinction in a changing environment: towards a predictive theory. PLoS Biology 8:31000357.

Christen, N., P. Calosi, C. L. McNeill, and S. Widdicombe. 2013. Structural and functional vulnerability to elevated $\mathrm{pCO}_{2}$ in marine benthic communities. Marine Biology 160:2113-2128.

Collins, S., and G. Bell. 2004. Phenotypic consequences of 1,000 generations of selection at elevated $\mathrm{CO}_{2}$ in a green alga. Nature 431:566-569.

Comeau, S., R. C. Carpenter, and P. J. Edmunds. 2013. Coral reef calcifiers buffer their response to ocean acidification using both bicarbonate and carbonate. Proceedings of the Royal Society B 280:20122374.

Connell, J. H. 1978. Diversity in tropical rain forests and coral reefs - high diversity of trees and corals is maintained only in a non-equilibrium state. Science 199:1302-1310.

Connell, J. H., and R. O. Slatyer. 1977. Mechanisms of succession in natural communities and their role in community stability. American Naturalist 111:1119-1144.

Connell, S. D., K. J. Kroeker, K. E. Fabricius, D. I. Kline, and B. D. Russell. 2013. The other ocean acidification problem: $\mathrm{CO}_{2}$ as a resource among competitors for ecosystem dominance. Philosophical Transactions of the Royal Society B 368:20120442. 
Connell, S. D., and B. D. Russell. 2010. The direct effects of increasing $\mathrm{CO}_{2}$ and temperature on non-calcifying organisms: increasing the potential for phase shifts in kelp forests. Proceedings of the Royal Society B 277:1409-1415.

Cornwall, C. E., C. D. Hepburn, D. Pritchard, K. I. Currie, C. M. McGraw, K. A. Hunter, and C. L. Hurd. 2012. Carbon-use strategies in macroalgae: differential responses to lowered $\mathrm{pH}$ and implications for ocean acidification. Journal of Phycology 48:137-144.

Cowen, R. K., C. B. Paris, and A. Srinivasan. 2006. Scaling of connectivity in marine populations. Science 311:522-527.

Crook, E. D., A. L. Cohen, M. Rebolledo-Vieyra, L. Hernandez, and A. Paytan. 2013. Reduced calcification and lack of acclimatization by coral colonies growing in areas of persistent natural acidification. Proceedings of the National Academy of the Sciences USA 110:11044-11049.

Dawson, M. N. 2014. Natural experiments and meta-analyses in comparative phylogeography. Journal of Biogeography 41:52-65.

Dayton, P. K. 1972. Toward and understanding of community resilience and the potential effects of enrichments to the benthos at McMurdo Sound Antarctica. Pages 81-96 in B. C. Parker, editor. Proceedings of the colloquium on conservation problems in Antarctica. Allen Press, Lawrence, Kansas, USA.

de Roos, A. M., and L. Persson. 2013. Population and community ecology of ontogenetic development. Princeton University Press, Princeton, New Jersey, USA.

Dineshram, R., V. Thiyagarajan, A. Lane, Y. Ziniu, S. Xiao, and P. T. Y. Leung. 2013. Elevated $\mathrm{CO}_{2}$ alters larval proteome and its phosphorylation status in the commercial oyster, Crassostrea hongkongensis. Marine Biology 16:21892205.

Doney, S. C., V. J. Fabry, R. A. Feely, and J. A. Kleypas. 2009. Ocean acidification: the other $\mathrm{CO}_{2}$ problem. Annual Review of Marine Science 1:169-192.

Doropoulos, C., S. Ward, A. Marshell, G. Diaz-Pulido, and P. J. Mumby. 2012. Interactions among chronic and acute impacts on coral recruits: the importance of size-escape thresholds. Ecology 93:2131-2138.

Dupont, S., O. Ortega-Martinez, and M. Thorndyke. 2010. Impact of near-future ocean acidification on echinoderms. Ecotoxicology 19:449-462.

Ellner, S. P. 2013. Rapid evolution: from genes to communities, and back again? Functional Ecology 27:1087-1099.

Fabricius, K. E., G. De'ath, S. Noonan, and S. Uthicke. 2014. Ecological effects of ocean acidification and habitat complexity on reef-associated macroinvertebrate communities. Proceedings of the Royal Society B 281:20132479.

Fabricius, K. E., C. Langdon, S. Uthicke, C. Humphrey, S. Noonan, G. De'ath, R. Okazaki, N. Muehllehner, M. S. Glas, and J. M. Lough. 2011. Losers and winners in coral reefs acclimatized to elevated carbon dioxide concentrations. Nature Climate Change 1:165-169.

Falkenberg, L. J., B. D. Russell, and S. D. Connell. 2013. Future herbivory: the indirect effects of enriched $\mathrm{CO}_{2}$ may rival its direct effects. Marine Ecology Progress Series 492:85-95.

Feely, R. A., C. L. Sabine, J. M. Hernandez-Ayon, D. Ianson, and B. Hales. 2008. Evidence for upwelling of corrosive "acidified" water onto the continental shelf. Science 320:1490-1492.

Figueiredo, J., A. H. Baird, S. Harii, and S. R. Connolly. 2014. Increased local retention of reef coral larvae as a result of ocean warming. Nature Climate Change 4:498-502.

Form, A. U., and U. Riebesell. 2012. Acclimation to ocean acidification during long-term $\mathrm{CO}_{2}$ exposure in the coldwater coral Lophelia pertusa. Global Change Biology 18:843853.

Frieder, C. A., J. P. Gonzalez, E. E. Bockmon, M. O. Navarro, and L. A. Levin. 2014. Can variable $\mathrm{pH}$ and low oxygen moderate ocean acidification outcomes for mussel larvae? Global Change Biology 20:754-764.

Gattuso, J.-P., M. Frankignoulle, I. Bourge, S. Romaine, and R. W. Buddemeier. 1998. Effect of calcium carbonate saturation of seawater on coral calcification. Global and Planetary Change 18:37-46.

Gaylord, B., and S. D. Gaines. 2000. Temperature or transport? Range limits in marine species mediated solely by flow. American Naturalist 155:769-789.

Gaylord, B., T. M. Hill, E. Sanford, E. A. Lenz, L. A. Jacobs, K. N. Sato, A. D. Russell, and A. Hettinger. 2011. Functional impacts of ocean acidification in an ecologically critical foundation species. Journal of Experimental Biology 214:2586-2594.

Gazeau, F., L. M. Parker, S. Comeau, J.-P. Gattuso, W. A. O'Connor, S. Martin, H.-O. Pörtner, and P. M. Ross. 2013. Impacts of ocean acidification on marine shelled molluscs. Marine Biology 160:2207-2245.

Giordano, M., J. Beardall, and J. A. Raven. 2005. $\mathrm{CO}_{2}$ concentrating mechanisms in algae: mechanisms, environmental modulation, and evolution. Annual Review of Plant Biology 56:99-131.

Godbold, J. A., and P. Calosi. 2013. Ocean acidification and climate change: advances in ecology and evolution. Philosophical Transactions of the Royal Society B 368:20120448.

Gooding, R. A., C. D. G. Harley, and E. Tang. 2009. Elevated water temperature and carbon dioxide concentration increase the growth of a keystone echinoderm. Proceedings of the National Academy of Sciences USA 106:9316-9321.

Gräns, A., et al. 2014. Aerobic scope fails to explain the detrimental effects on growth resulting from warming and elevated $\mathrm{CO}_{2}$ in Atlantic halibut. Journal of Experimental Biology 217:711-717.

Green, M. A., G. G. Waldbusser, L. Hubazc, E. Cathcart, and J. Hall. 2013. Carbonate mineral saturation state as the recruitment cue for settling bivalves in marine muds. Estuaries and Coasts 36:18-27.

Guinotte, J. M., J. Orr, S. Cairns, A. Freiwald, L. Morgan, and R. George. 2006. Will human-induced changes in seawater chemistry alter the distribution of deep-see scleractinian corals? Frontiers in Ecology and the Environment 4:141-146.

Hale, R., P. Calosi, L. McNeill, N. Mieszkowska, and S. Widdicombe. 2011. Predicted levels of future ocean acidification and temperature rise could alter community structure and biodiversity in marine communities. Oikos 120:661-674.

Hall-Spencer, J. M., R. Rodolfo-Metalpa, S. Martin, E. Ransome, M. Fine, S. M. Turner, S. J. Rowley, D. Tedesco, and M.-C. Buia. 2008. Volcanic carbon dioxide vents show ecosystem effects of ocean acidification. Nature 454:96-99.

Hammill, E., O. L. Petchey, and B. R. Anhold. 2010. Predator functional response changed by induced defenses of prey. American Naturalist 176:723-731.

Hanski, I. 1998. Metapopulation dynamics. Nature 396:41-49. Harley, C. D. G., K. M. Anderson, K. W. Demes, J. P. Jorve, R. L. Kordas, and T. A. Coyle. 2012. Effects of climate change of global seaweed communities. Journal of Phycology 48:1064-1078.

Hauri, C., N. Gruber, M. Vogt, S. C. Doney, R. A. Feely, Z. Lachkar, A. Leinweber, A. M. P. McDonnell, M. Munnich, and G.-K. Plattner. 2013. Spatiotemporal variability and long-term trends of ocean acidification in the California Current System. Biogeosciences 10:193-216.

Hepburn, C. D., D. W. Pritchard, C. E. Cornwall, R. J. McLeod, J. Beardall, J. A. Raven, and C. L. Hurd. 2011. Diversity of carbon use strategies in a kelp forest community: implications for a high $\mathrm{CO}_{2}$ world. Global Change Biology 17:2488-2497.

Hettinger, A., E. Sanford, T. M. Hill, A. D. Russell, K. N. S. Sato, J. Hoey, M. Forsch, H. N. Page, and B. Gaylord. 2012. 
Persistent carry-over effects of planktonic exposure to ocean acidification in the Olympia oyster. Ecology 93:2758-2768.

Hoegh-Guldberg, O., et al. 2007. Coral reefs under rapid climate change and ocean acidification. Science 318:17371742.

Hofmann, G. E., J. P. Barry, P. J. Edmunds, R. D. Gates, D. A. Hutchins, T. Klinger, and M. A. Sewell. 2010. The effect of ocean acidification on calcifying organisms in marine ecosystems: An organism-to-ecosystem perspective. Annual Review of Ecology, Evolution, and Systematics 41:127-147.

Hofmann, G. E., et al. 2011. High-frequency dynamics of ocean pH: A multi-ecosystem comparison. PLoS ONE 6:e28983.

Hönisch, B., et al. 2012. The geological record of ocean acidification. Science 335:1058-1063.

Huston, M. 1979. A general hypothesis of species diversity. American Naturalist 113:81-101.

Ives, A. R., and B. J. Cardinale. 2004. Food-web interactions govern the resistance of communities after non-random extinctions. Nature 429:174-177.

Kelly, M. W., J. L. Padilla-Gamino, and G. E. Hofmann. 2013. Natural variation and the capacity to adapt to ocean acidification in the keystone sea urchin Strongylocentrotus purpuratus. Global Change Biology 19:2536-2546.

Koch, M. G. C. Ross, Bowes, and X.-H. Zhang. 2013. Climate change and ocean acidification effects on seagrasses and marine macroalgae. Global Change Biology 19:103-132.

Kooijman, S. A. L. M. 2010. Dynamic energy budget theory for metabolic organization. Cambridge University Press, Cambridge, UK.

Kroeker, K. J., R. L. Kordas, R. Crim, I. E. Hendriks, L. Ramajo, G. S. Singh, C. M. Duarte, and J. P. Gattuso. 2013a. Impacts of ocean acidification on marine organisms: quantifying sensitivities and interaction with warming. Global Change Biology 19:1884-1896.

Kroeker, K. J., R. L. Kordas, R. N. Crim, and G. G. Singh. 2010. Meta-analysis reveals negative yet variable effects of ocean acidification on marine organisms. Ecology Letters 13:1419-1434.

Kroeker, K. J., F. Micheli, and M. C. Gambi. 2013b. Ocean acidification causes ecosystem shifts via altered competitive interactions. Nature Climate Change 3:156-159.

Kroeker, K. J., F. Micheli, M. C. Gambi, and T. R. Martz. 2011. Divergent ecosystem responses within a benthic marine community to ocean acidification. Proceedings of the National Academy of Sciences USA 108:14515-14520.

Kuffner, I. B., A. J. Andersson, P. L. Jokiel, K. S. Rodgers, and F. T. Mackenzie. 2008. Decreased abundance of crustose coralline algae due to ocean acidification. Nature Geoscience $1: 114-117$.

Lande, R. 2009. Adaptation to an extraordinary environment by evolution of phenotypic plasticity and genetic assimilation. Journal of Evolutionary Biology 22:1435-1446.

Leibold, M. A. 1996. A graphical model of keystone predators in food webs: trophic regulation of abundance, incidence, and diversity patterns in communities. American Naturalist 147:784-812.

Locke, A., and W. G. Sprules. 2000. Effects of acidic pH and phytoplankton on survival and condition of Bosmina longirostris and Daphnia pulex. Hydrobiologia 437:187-196.

Lohbeck, K. T., U. Riebesell, and T. B. H. Reusch. 2012. Adaptive evolution of a key phytoplankton species to ocean acidification. Nature Geoscience 5:346-351.

Loreau, M., et al. 2001. Biodiversity and ecosystem functioning: current knowledge and future challenges. Science 294:804808.

MacArthur, R. 1970. Species packing and competitive equilibrium for many species. Theoretical Population Biology $1: 1-11$

MacLeod, C. D., and R. Poulin. 2012. Host-parasite interactions: a litmus test for ocean acidification? Trends in Parasitology 28:365-369.
McCormick, M. I., S.-A. Watson, and P. L. Munday. 2013. Ocean acidification reverses competition for space as habitats degrade. Scientific Reports 3:3280.

McCoy, S. J., and C. A. Pfister. 2014. Historical comparisons reveal altered competitive interactions in a guild of crustose coralline algae. Ecology Letters 17:475-483.

Menge, B. A., and J. P. Sutherland. 1987. Community regulation: variation in disturbance, competition, and predation in relation to environmental stress and recruitment. American Naturalist 130:730-757.

Milazzo, M., R. Rodolfo-Metalpa, V. B. S. Chan, M. Fine, C. Alessi, V. Thiyagarajan, J. M. Hall-Spencer, and R. Chemello. 2014. Ocean acidification impairs vermetid reef recruitment. Scientific Reports 4:4189.

Miller, A. W., A. C. Reynolds, C. Sobrino, and G. F. Riedel. 2009. Shellfish face uncertain future in high $\mathrm{CO}_{2}$ world: Influence of acidification on oyster larvae calcification and growth in estuaries. PLoS ONE 4:e5661.

Muller, E. B., and R. M. Nisbet. 2014. Dynamic energy budget modeling reveals the potential of future growth and calcification for the coccolithophore Emiliania huxleyi in an acidified ocean. Global Change Biology 20:2031-2038.

Munday, P. L., D. L. Dixson, M. I. McCormick, M. Meekan, M. C. O. Ferrari, and D. P. Chivers. 2010. Replenishment of fish populations is threatened by ocean acidification. Proceedings of the National Academy of Sciences USA 107:12930-12934.

Munday, P. L., R. R. Warner, K. Monro, J. M. Pandolfi, and D. J. Marshall. 2013. Predicting evolutionary responses to climate change in the sea. Ecology Letters 16:1488-1500.

Narayan, N., A. Paul, S. Mulitza, and M. Schulz. 2010. Trends in coastal upwelling intensity during the late 20th century. Ocean Science 6:815-823.

Nilsson, G. E., D. L. Dixson, P. Domenici, M. I. McCormick, C. Sorensen, S.-A. Watson, and P. L. Munday. 2012. Nearfuture carbon dioxide levels alter fish behavior by interfering with neurotransmitter function. Nature Climate Change 2:201-204.

Nisbet, R. M., and W. S. C. Gurney. 1982. Modelling fluctuations populations. Wiley, New York, New York, USA.

O’Connor, M. I., J. F. Bruno, S. D. Gaines, B. S. Halpern, S. E. Lester, B. P. Kinlan, and J. M. Weiss. 2007. Temperature control of larval dispersal and the implications for marine ecology, evolution, and conservation. Proceedings of the National Academy of Sciences USA 104:1266-1271.

O’Donnell, M. J., M. N. George, and E. Carrington. 2013. Mussel byssus attachment weakened by ocean acidification. Nature Climate Change 3:587-590.

Oksanen, L., S. D. Fretwell, J. Arruda, and P. Niemela. 1981. Exploitation ecosystems in gradients of primary productivity. American Naturalist 118:240-261.

Paine, R. T. 1969. A note on trophic complexity and community stability. American Naturalist 103:91-93.

Palacios, S. L., and R. C. Zimmerman. 2007. Response of eelgrass Zostera marina to $\mathrm{CO}_{2}$ enrichment: possible impacts of climate change and potential for remediation of coastal habitats. Marine Ecology Progress Series 344:1-13.

Parker, L. M., P. M. Ross, W. A. O'Connor, L. Borysko, D. A. Raftos, and H.-O. Pörtner. 2012. Adult exposure influences offspring response to ocean acidification in oysters. Global Change Biology 18:82-92.

Parmesan, C., and G. Yohe. 2003. A globally coherent fingerprint of climate change impacts across natural systems. Nature 421:37-42.

Perry, A. L., P. J. Low, J. R. Ellis, and J. D. Reynolds. 2005. Climate change and distribution shifts in marine fishes. Science 308:1912-1915.

Pespeni, M. H., et al. 2013. Evolutionary change during experimental ocean acidification. Proceedings of the National Academy of Sciences USA 110:6937-6942. 
Poloczanska, E. S., et al. 2013. Global imprint of climate change on marine life. Nature Climate Change 4:919-925.

Pörtner, H.-O. 2008. Ecosystem effects of ocean acidification in times of ocean warming: a physiologist's view. Marine Ecology Progress Series 373:203-217.

Rees, M., D. Z. Childs, and S. P. Ellner. 2014. Building integral projection models: a user's guide. Journal of Animal Ecology 83:528-545.

Ries, J. B. 2011. A physiochemical framework for interpreting the biological calcification response to $\mathrm{CO}_{2}$-induced ocean acidification. Geochemica et Cosmochimica Acta 75:40534064.

Rossoll, D., R. Bermudez, H. Hauss, K. G. Schulz, U. Riebesell, U. Sommer, and M. Winder. 2012. Ocean acidification-induced food quality deterioration constrains trophic transfer. PLoS ONE 7:e34737.

Roughgarden, J., Y. Iwasa, and C. Baxter. 1985. Demographic theory for an open marine population with space-limited recruitment. Ecology 66:54-67.

Rumrill, S. S. 1990. Natural mortality of marine invertebrate larvae. Ophelia 32:163-198.

Russell, B. D., C. D. G. Harley, T. Wernberg, N. Mieszkowska, S. Widdicombe, J. M. Hall-Spencer, and S. D. Connell. 2012. Predicting ecosystem shifts requires new approaches that integrate the effects of climate change across entire systems. Biology Letters 8:164-166.

Russell, B. D., J.-A. I. Thompson, L. J. Falkenberg, and S. D. Connell. 2009. Synergistic effects of climate change and local stressors: $\mathrm{CO}_{2}$ and nutrient-driven change in subtidal rocky habitats. Global Change Biology 15:2153-2162.

Sanford, E., B. Gaylord, A. Hettinger, E. A. Lenz, K. Meyer, and T. M. Hill. 2014. Ocean acidification increases the vulnerability of native oysters to predation by invasive snails. Proceedings of the Royal Society B 281:20132681.

Schoener, T. W. 2011. The newest synthesis: understanding the interplay of evolutionary and ecological dynamics. Science 331:426-429.

Shurin, J. B., D. S. Gruner, and H. Hillebrand. 2002. All wet or dried up? Real differences between aquatic and terrestrial food webs. Proceedings of the Royal Society B 273:1-9.

Snyder, M. A., L. C. Sloan, N. S. Diffenbaugh, and J. L. Bell. 2003. Future climate change and upwelling in the California Current. Geophysical Research Letters. http://dx.doi.org/10. 1029/2003GL017647

Sousa, W. P. 1979a. Disturbance in marine intertidal boulder fields: the non-equilibrium maintenance of species diversity. Ecology 60:1225-1239.

Sousa, W. P. 1979b. Experimental investigations of disturbance and ecological succession in a rocky intertidal algal community. Ecological Monographs 49:227-254.

Strong, D. R. 1992. Are trophic cascades all wet: differentiation and donor-control in speciose ecosystems. Ecology 73:747754.

Sunday, J. M., A. E. Bates, and N. K. Dulvy. 2012. Thermal tolerance and the global redistribution of animals. Nature Climate Change 2:686-690.

Sunday, J. M., P. Calosi, S. Dupont, P. L. Munday, J. H. Stillman, and T. B. H. Reusch. 2014. Evolution in an acidifying ocean. Trends in Ecology and Evolution 29:117125.

Sunday, J. M., R. N. Crim, C. D. G. Harley, and M. W. Hart. 2011. Quantifying rates of evolutionary adaptation in response to ocean acidification. PLoS ONE 6:e22881.

Talmage, S. C., and C. J. Gobler. 2010. Effects of past, present, and future ocean carbon dioxide concentrations of the growth and survival of larval shellfish. Proceedings of the National Academy of Sciences USA 107:17246-17251.

Thomas, C. D., et al. 2004. Extinction risk from climate change. Nature 427:145-148.

Thomsen, J., I. Casties, C. Pansch, A. Kortzinger, and F. Melzner. 2013. Food availability outweighs ocean acidification effects in juvenile Mytilus edulis: laboratory and field experiments. Global Change Biology 19:1017-1027.

Trussell, G. C. 1996. Phenotypic plasticity in an intertidal snail - the role of a common crab predator. Evolution 50:448-454.

Vaz-Pinto, F., C. Olabarria, I. Gestoso, E. Cacabelos, M. Incera, and F. Arena. 2013. Functional diversity and climate change: effects on the invasibility of macroalgal assemblages. Biological Invasions 15:1833-1846.

Waldbusser, G. G., E. L. Brunner, B. A. Haley, B. Hales, C. J. Langdon, and F. G. Prahl. 2013. A developmental and energetic basis linking larval oyster shell formation to acidification sensitivity. Geophysical Research Letters 40:2171-2176.

Watson, S.-A., S. Lefevre, M. I. McCormick, P. Domenici, G. E. Nilsson, and P. L. Munday. 2014. Marine mollusc predator-escape behaviour altered by near-future carbon dioxide levels. Proceedings of the Royal Society B 281:20132377.

Webster, N. S., S. Uthicke, E. S. Botte, F. Flores, and A. P. Negri. 2013. Ocean acidification reduces induction of coral settlement by crustose coralline algae. Global Change Biology 19:303-315.

Werner, E. E., and S. D. Peacor. 2003. A review of traitmediated indirect interactions in ecological communities. Ecology 84:1083-1100.

Widdicombe, S., and J. Spicer. 2008. Predicting the impact of ocean acidification on benthic biodiversity: What can animal physiology tell us? Journal of Experimental Marine Biology and Ecology 366:187-197.

Wootton, J. T. 1994. The nature and consequences of indirect effects in ecological communities. Annual Review of Ecology and Systematics 25:443-466.

Wootton, J. T., C. A. Pfister, and J. D. Forester. 2008. Dynamic patterns and ecological impacts of declining ocean $\mathrm{pH}$ in a high-resolution multi-year dataset. Proceedings of the $\mathrm{Na}-$ tional Academy of Sciences USA 105:18848-18853.

Wootton, J. T., and M. E. Power. 1993. Productivity, consumers, and the structure of a river food-chain. Proceedings of the National Academy of Sciences USA 90:13841387.

Yachi, S., and M. Loreau. 1999. Biodiversity and ecosystem productivity in a fluctuating environment: The insurance hypothesis. Proceedings of the National Academy of Sciences USA 96:1463-1468. 